\title{
Género, discurso y transgresión femenina en la antigua Grecia:
}

\section{la figura de Clitemnestra}

Paula Quintano Martínez

al321700@uji.es 


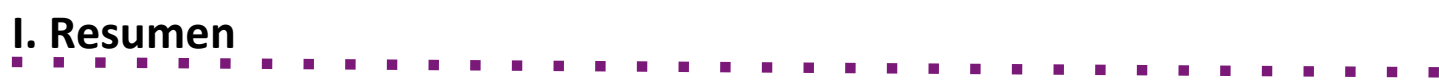

La cultura clásica ha sido generadora de construcciones de lo femenino y lo masculino que han perdurado en nuestro inconsciente colectivo, incluso algunas convertidas en imágenes arquetípicas.

Esta investigación es deudora de la historia de género y se relaciona con las corrientes de análisis histórico que rescatan el valor de la palabra y los discursos desde una nueva perspectiva: comprender tanto las argumentaciones acerca de la diferencia entre hombres y mujeres como las prácticas de desigualdad de género establecidas en el pasado y que, de algún modo, siguen aún presentes.

Bajo la premisa de que el acceso de las mujeres a una voz propia puede implicar una poderosa vía de subversión, la palabra y la voz femenina se consideran desde una perspectiva multidisciplinar como herramientas transgresoras en la antigua Grecia, precisamente en una sociedad en la que la imposición del silencio se convirtió en una constante de la vida de las mujeres.

El estudio se inicia con una revisión sobre las convenciones y los estereotipos de género que rigieron en el mundo heleno. Continúa con un análisis sobre el ejercicio de la palabra como derecho y privilegio distintivo del estatus ciudadano, del que las mujeres fueron insistentemente apartadas. Y, para finalizar, se traslada en torno a la figura de Clitemnestra, personaje mítico y literario femenino que ha pasado a la historia como paradigma de "mujer fatal», a menudo simplificado como representante de "las perversas». La combinación, re-lectura y análisis profundo de las fuentes disponibles (literarias, arqueológicas, plásticas) permiten rescatar la complejidad de esta figura que personifica un proceso transgresor multifacético frente a los conceptos clave del ideal femenino. $Y$ posibilitan reconsiderar la validez de la palabra como instrumento femenino de desobediencia.

Palabras clave: discurso, tragedia, Clitemnestra, transgresión de género, antigua Grecia, estereotipos de género, literatura griega.

\section{Introducción}

El mundo europeo hunde sus raíces en la civilización grecorromana, y su influencia en nuestra manera de entender el mundo y de organizar nuestras sociedades ha sido tan intensa que todavía perviven ciertas inercias generadas en la antigüedad. Además, somos conscientes de la dificultad de acceder a las voces de las mujeres a lo largo de la historia y de la constante imposición del silencio en la vida femenina. Una exigencia especialmente manifiesta 
en el escenario de nuestra investigación, la antigua Grecia, que nos ha animado a estudiar la apropiación de la palabra y la conquista de una voz propia como estrategias femeninas de transgresión.

Pondremos de relieve cómo el mundo del conocimiento y de la cultura ha sido un terreno en el que los estereotipos sobre lo femenino y lo masculino y las distintas capacidades otorgadas a mujeres y hombres tuvieron una tremenda influencia. De hecho, reconocer la factura masculina de la mayor parte de las fuentes de nuestra investigación implica asumir que la práctica totalidad de ideas sobre las mujeres que quedaron registradas estuvieron mediatizadas; incluso las palabras y opiniones en boca de las propias mujeres lo estarían, ya que fueron los hombres quienes monopolizaron el discurso, la lectura y la escritura, y así controlaban los medios de expresión (Duby y Perrot, 1991: 10).

Precisamente, cuestiones como el acceso al ejercicio de la palabra representan nuevos frentes en la historia antigua. Se procura examinar las circunstancias que rodearon las voces de las mujeres, los procesos de toma de la palabra y analizar todo aquello que se relacionara con sus discursos. Desde esta perspectiva se entiende que existen otras formas más allá del significado tradicional de poder como sinónimo de dominación (Mirón Pérez, 2010). En concreto, el poder o la autoridad que emanan del conocimiento, de la facultad de ejercer la palabra, de la licencia o el derecho a hablar, a ser escuchado y a silenciar.

El lenguaje y el discurso resultan piezas esenciales para la reconstrucción histórica, pues son "conformadores de realidades históricas»: porque las personas de cualquier época no se limitan a reflejar la realidad sino que la construyen a través de sus palabras. Igual que la reconstruimos quienes nos dedicamos al análisis de la historia. Por ello, a lo largo de la investigación, planteamos cómo los discursos pueden vehicularse desde una doble vía: bien para legitimar los códigos culturales, sociales y políticos imperantes, o bien para contradecirlos, socavando su legitimidad y creando frentes de resistencia a las convenciones establecidas.

Sostenemos que la palabra se puede utilizar desde una nueva perspectiva para reconstruir la vida de las mujeres en el pasado. $Y$, en este caso específicamente, como una vía que asocie la voz femenina a tramas de desobediencia. Porque en una sociedad como la griega, en la que el silencio se entendía como cualidad femenina esencial y requisito innegociable para las mujeres, el mero acto de alzar la voz y hablar en público podría considerarse un acto subversivo e implicaba una fuerte transgresión de las convenciones de género.

Con frecuencia se ha relacionado el amplio desarrollo cultural de Grecia con los avances en la alfabetización, entre otros motivos gracias a la difusión del nuevo alfabeto que, desarrollado en torno al 
800 a. C., convirtió la escritura y la lectura en actividades más sencillas (Pomeroy, 2001: 103). El proceso de difusión de la lectoescritura, aunque fue cuantitativamente minoritario, resultó cualitativamente intenso y su honda repercusión posibilita estudiar la palabra registrada ya a modo de texto y permite relacionar la esfera discursiva con el mundo de la escritura en cualquiera de sus vertientes (literaria, filosófica, histórica).

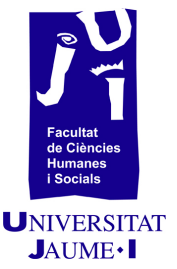

\section{Objetivos}

El contexto general de la investigación marca la necesidad de situar a las mujeres junto a los hombres como protagonistas activas y agentes en el devenir histórico, al entender que ambos han sido motores de la historia y actores modelados por el género (Rose, 2012). Partimos de la premisa de que las personas somos seres definidos en términos de género: a mujeres y hombres se nos otorgan unas características que terminan por percibirse como particularidades distintivas de cada sexo (asociadas a lo femenino y a lo masculino) y modulan la manera de construir nuestras relaciones. Son diferencias socialmente construidas en función de los grupos humanos y las variables del tiempo y del espacio.

Nuestro propósito fundamental era examinar cómo la palabra en manos femeninas podía convertirse en un potente instrumento subversivo, dado que, en el mundo griego, la autoridad del discurso y el derecho a ser escuchado se asoció de forma casi exclusiva a los ciudadanos varones. $Y$ especialmente nos interesaba analizar alguna figura femenina que se hubiera adueñado de la palabra pública desafiando la ideología dominante que había expulsado a las mujeres del lenguaje y del poder que otorgaba.

Con tal fin tomamos a Clitemnestra como personaje femenino relevante del universo mítico y literario heleno para realizar un análisis minucioso de su figura a través de los distintitos retratos que de ella habían sobrevivido. Queríamos redibujar su esencia en busca de sus rasgos transgresores y confrontarla con el ideal de mujer establecido en el ideario griego.

\section{Fuentes y método}

La investigación descansa sobre unas coordenadas espaciotemporales amplias: cronológicamente comprende desde el periodo arcaico hasta el periodo helenístico y no se circunscribe a una comunidad concreta, sino que incluye a todo el mundo heleno. Es una elección que casaba a la perfección con la vista mosaico que 
se buscaba transmitir: permitía aprovechar la amplitud del marco geográfico y cronológico para ofrecer una visión más completa y poder establecer comparaciones entre distintos periodos históricos e identificar matices entre las distintas comunidades helenas. Porque la situación sociopolítica fue variando en función del tiempo y del espacio y los cambios también se reflejaron en el plano ideológico; sobre todo tras la aparición de la polis o ciudad-estado (750-700 a. C.) y su posterior asentamiento como organización politicosocial característica del mundo griego hasta bien entrada la época romana; y, por supuesto, también tras el desarrollo del sistema democrático como sistema político significativo, sobre todo a lo largo del siglo $\mathrm{V}$ a. C., y con el apogeo del concepto de ciudadanía, que otorgaba la capacidad de participar en la vida pública de la ciudad y la dirección colaborativa del estado. $Y$ todo sin olvidar las profundas transformaciones producidas a partir de la época helenística, en la que el papel de la ciudadanía va disminuyendo y las sociedades griegas se vuelven más porosas a los influjos exteriores, hasta la dominación romana del territorio heleno.

La mayor parte de fuentes de análisis que se han manejado han sido de naturaleza escrita: principalmente fuentes literarias complementadas con otras de carácter histórico y filosófico. Sobre todo se ha recurrido a la tragedia y en menor medida a los géneros épico y lírico. Ciertas obras se han utilizado como textos de cabecera y merecen especial mención por el uso intensivo que se ha hecho: la Odisea, de Homero (s. VIII a. C.); la Orestea, de Esquilo, trilogía compuesta por las obras Agamenón, Coéforas y Euménides (c. 458 a. C.); la obra Píticas XI, del poeta Píndaro (474 a. C.); además de las tragedias con el título Electra que comparten las obras de Sófocles (c. 415-413 a. C.) y Eurípides (c. 417-413 a. C.).

Junto a la información textual, se ha integrado el análisis de otros testimonios como los arqueológicos, epigráficos y plásticos que a menudo revelan una intensa relación con la vida social y por ello resultan muy útiles para observar la articulación entre lo femenino y lo masculino.

De todas formas, en lo relativo a las fuentes, hemos sido conscientes de que gran parte de lo que ha sobrevivido se refiere de forma exclusiva al ámbito ateniense, una de las realidades del mundo heleno sobre la que existen más datos y un mayor nivel de conocimiento. Otras realidades de la antigua Grecia, como la espartana -o más aún, la cretense-, siguen siendo menos conocidas, tanto por la falta de fuentes como por el sesgo de la información conservada. Por ello, se ha tenido en cuenta que las conclusiones extraídas de la esfera ateniense no pueden ni deben extrapolarse directamente al resto del mundo griego sin un análisis más profundo que considere las singularidades de cada comunidad helena. 
A la hora de valorar las fuentes, se han seguido dos criterios esenciales. Por una parte, ser conscientes de la escasez de testimonios directos en los que las mujeres hayan sido las protagonistas y prudentes ante la ausencia de fuentes de factura femenina, por lo que la información registrada y conservada debe tomarse con reservas. Por otra, entender que contamos con representaciones y evidencias indirectas, es decir, contadas y recogidas no por las propias protagonistas, sino por otros narradores que, casi invariablemente, fueron hombres. Así que resulta imprescindible tener presente que las fuentes, ya sean literarias o plásticas, no responden a una translación objetiva de la realidad, sino que fueron fruto de una visión particular, una mirada que readaptaba la realidad con una intencionalidad determinada. En ocasiones, proporcionan una información más pedagógica que meramente narrativa; en otras, llegan a tener un marcado carácter moralizante. En definitiva, la finalidad de la gran mayoría no es otra que la de reafirmar las convenciones sociales y culturales establecidas.

En concreto, la literatura griega no es una fuente histórica ni ofrece un retrato objetivo de la realidad de las mujeres: con frecuencia recrea protagonistas difícilmente asimilables a las clases populares y más fácilmente asociables a las clases dirigentes; además, por su frecuente recurso al mundo mítico suelen parecer lejanas al común de los mortales. También es habitual que atribuya a las mujeres la consideración de "colectividad invariable», dotada de ciertas cualidades comunes. Pero su tradición generalizadora permite descubrir los estereotipos que sobre la mujer y lo femenino se construyeron y transmitieron. Por ello, puede considerarse una vía importante para rastrear la ideología de género en la antigua Grecia.

La necesidad de trabajar con fuentes diversas ha abierto la posibilidad de establecer comparaciones en el tratamiento de los temas. De hecho, la idea que anima la investigación es la confrontar la información conservada en diferentes formatos para cuestionar las interpretaciones inmediatas, pues la comparación de ciertas fuentes tras un primer análisis directo puede llegar a inducir conclusiones contradictorias. Al acometer la lectura de los textos y de los restos conservados, se ha planteado la necesidad de considerar más allá de lo que a simple vista se percibe. Se buscaba tener en cuenta las trampas del lenguaje, tanto escrito como visual. Por eso, se han practicado segundas lecturas o relecturas, precisamente para analizar los significados de lo que se dijo y lo que se quiso decir, de lo que se ve y lo que se quiso representar. En definitiva, se ha valorado especialmente la autoría, la intencionalidad y la función de cada una de las fuentes.

Se trata de analizar la voz femenina desde una perspectiva multidisciplinar, conectando los estudios históricos con los 
mitológicos, literarios, lingüísticos y antropológicos, y acompañando la revisión de las fuentes con reflexiones personales. En realidad, se ha llevado a cabo una revisión y relectura de las fuentes aplicando la perspectiva de género; porque en el ámbito metodológico el enfoque se perfila desde ese prisma, entendiendo el género como una categoría esencial de análisis histórico (Scott, 1990: 44). Es un concepto que nos permite conocer las maneras en que las sociedades ordenan las relaciones entre mujeres y hombres, que lejos de ser simétricas se han establecido de forma asimétrica y jerárquica.

Sin embargo, ni la consideración de mujer y de hombre, ni las interpretaciones de la feminidad y la masculinidad han sido categorías invariables. Ni siquiera las categorías de mujer y hombre pueden considerarse nociones monolíticas puesto que no funcionan de la misma manera para todas las mujeres y todos los hombres en una misma sociedad y en el mismo momento histórico (Rose, 2012: 85). En el pasado también existió una diversidad de hombres y mujeres y diversas maneras de construir lo femenino y lo masculino. Porque el género se interrelaciona con otras categorías de significación social relevantes para el análisis histórico como el estatus, la posición socioeconómica, la etnia, la edad. Todas estas categorías sociales se superponen e influyen de manera combinada en la creación de los códigos culturales que dictan cómo deben ser las mujeres y los hombres.

\section{Partes de la investigación}

El estudio se divide en tres capítulos entendidos como un recorrido desde lo general a lo particular. Los dos primeros bloques de contenido están dedicados, por una parte, a las convenciones y los estereotipos de género $y$, por otra, a la relación que podría establecerse entre la palabra y el género dentro del mundo griego. Ambos capítulos corresponden a contenidos de carácter más bien genéricos que establecen el marco conceptual de análisis para la tercera parte. Esta última sección está dedicada casi íntegramente a la figura de Clitemnestra, que se estudia a través de los diferentes retratos literarios y plásticos conservados.

El primer capítulo representa la base de la investigación. Comienza con un repaso a la construcción de la diferencia sexual en la antigua Grecia, resaltando la influencia de llamada «lógica de polarización de contrarios» que parece caracterizar el pensamiento griego. Esta construcción simbólica conllevó una visión dual del mundo dividido en dos esferas opuestas a las que se asociaron lo masculino y lo femenino, y, por extensión, el hombre y la mujer. Entre estos contrarios se instauraba una relación asimétrica en la que 
el varón y lo masculino se entendían como modelo de lo humano y, por extensión, de todas las cosas. El hombre se consideraba superior y dominante, mientras que la mujer y lo femenino representaban la inferioridad y la subordinación, como inadecuación frente a la perfección masculina (Sissa, 1991: 94).

Se ha destacado cómo los estereotipos de género se construyeron en torno a esas características asociadas a hombres y a mujeres. A modo de contexto, se ha trazado un recorrido a lo largo del cual se analizan cuatro temas considerados esenciales para los roles de género. Primero se ha fijado la visión sobre el estatus femenino y la situación politicolegal de las mujeres en el mundo griego. En segundo lugar, se ha realizado un repaso de los roles políticos y sociales de mujeres y hombres desde la óptica de la ciudadanía, puesto que el ideal griego reglamentó la comunidad estableciendo una clara división de responsabilidades según el sexo. El tercer punto ha revisado la tradicional visión dicotómica del espacio en el ideario griego: la polaridad entre lo público y lo privado; lo exterior, que contraponía idealmente los asuntos públicos de la ciudad, la polis, y el mundo interior y privado del hogar, el oikos, como espacios masculino y femenino. A este respecto interesaba indagar hasta qué punto ese modelo ideal podría tomarse como una representación literal de los comportamientos reales, y también preguntarse acerca de la proporción de mujeres que habría observado estos ideales (Davidson, 2011). El cuarto y último punto de reflexión se ha centrado en el concepto de respetabilidad social, una idea que tendrá fuertes implicaciones en los roles de género que normativizaron la sociedad griega, y especialmente en la vida de las mujeres. Porque, a medida que el sistema democrático se consolidó, se fue acometiendo un proceso de diferenciación entre las mujeres respetables y las no respetables: se llegó a practicar una supervisión recurrente de la respetabilidad femenina y más específicamente de la decencia de las mujeres «ciudadanas».

El segundo capítulo gira en torno a la palabra, el discurso y sus implicaciones con el género. Se inicia con un estudio sobre la importancia de la palabra en el mundo griego con el fin de valorar el grado de exclusión al que las mujeres fueron sometidas tras ser apartadas del mundo del conocimiento y del discurso. Fue una expulsión que se sustentó en diversos ámbitos: el ámbito politicoadministrativo de la polis, la vida cultural y el mundo educativo y del conocimiento. Porque la palabra se entendió como elemento diferenciador entre lo humano y lo animal, y el derecho a ejercitarla se convirtió en uno de los ingredientes distintivos entre el varón y la mujer y en instrumento de poder supremo dentro de la polis (Vernant, 1992: 61). En una sociedad que reivindicó la palabra como derecho ciudadano distintivo y excluyente, en la que ser ciudadano equivalía a tener la capacidad de tomar parte en la 
comunidad a través del ejercicio de la palabra, las mujeres quedaron definidas por el requisito del silencio y la ignorancia en una especie de mudez social impuesta bajo las cualidades de la discreción, la prudencia, la docilidad y la obediencia. De hecho, la misma educación femenina enseñaba a obedecer las normas y adiestraba para perpetuar las convenciones de género.

Siguiendo la premisa de buscar matices, se ha señalado como excepción el importante papel público de las mujeres en el orden social y en la esfera cívica espartana: su implicación en distintas actividades culturales comunitarias y el acceso al conocimiento que tenían gracias a la educación habrían marcado una de las grandes diferencias en la vida de las mujeres en Esparta (Pomeroy, 2002). Al menos en estos ámbitos representarían las antípodas del resto del territorio heleno.

Pero fuera del ámbito dorio, las mujeres, que no gozaban de autoridad reconocida en contextos públicos, carecieron del derecho a pronunciarse $y$, lo que es más, adolecieron del derecho a ser escuchadas. Porque al verse privadas de la palabra se les impuso un silencio que acabó por convertirse en virtud y signo de respetabilidad. De hecho, una de las normas de género principales en el mundo griego -exceptuando Esparta y el ámbito dorio- podría resumirse en la fórmula «las mujeres no debían ser vistas, ni debían hablar ni debía hablarse de ellas» (Blok, 2001: 97). Como última parte de este bloque de contenido se han recordado las consideraciones sobre la existencia de "sexolectos» en el mundo griego (Quintillá, 2005), es decir, la existencia de una caracterización lingüística del habla femenina, diferenciada $y$, en cierta manera, contrapuesta al lenguaje masculino.

La investigación se cierra con un último capítulo dedicado de lleno a revisar la figura de Clitemnestra. La perspectiva de estudio del personaje pretende recuperar sus atributos esenciales y sus características transgresoras. La idea fundamental reside en establecer un retrato robot de nuestra protagonista para poder confrontarlo con el ideal de mujer establecido por el ideario griego. Así, se han buscado los rasgos distintivos comunes que comparten las fuentes literarias disponibles; en concreto a través de los retratos ofrecidos por Homero, Esquilo, Píndaro, Sófocles y Eurípides. Para dibujar a Clitemnestra, también se ha recurrido a las representaciones plásticas del ciclo de la Orestea, que si bien no son numéricamente muy abundantes, llegaron a convertirse en ejemplos iconográficos identificativos (Dukelsky, 2011); porque, a pesar de que las artes plásticas tienen un lenguaje propio y los artistas recrearon los mitos agregando sus propios ingredientes y particularidades como lo hicieron los escritores en el caso de las obras literarias-, se pueden descubrir marcas comunes en la representación de Clitemnestra. 
Para retratarla, se ha comenzado por analizar los apelativos más frecuentes con los que se refieren a ella en las distintas obras y significativamente se comprueba la ausencia de epítetos positivos. De forma especial, el estudio remarca cómo las fuentes se refieren a su lenguaje y a su forma de hablar; porque si algo destaca del carácter de Clitemnestra es su dominio absoluto del lenguaje: domina la palabra bajo un prisma doble. Por un lado, practica formas de comunicación tradicionalmente asociadas a lo femenino, como un lenguaje simbólico de tintes mágicos y un habla seductora, ambigua y engañosa (Iriarte, 1990), y se le considera una maestra del engaño. Sin embargo, por otro lado, significativamente se muestra versada en la oratoria, arte que de forma invariable se hacía unir al universo masculino. $Y$ es que su figura es representada en la mayor parte de las obras como una mujer virilizada y asociada a lo masculino, incluso iconográficamente.

Clitemnestra, que acomete su venganza personal ajusticiando a su marido Agamenón, es juzgada socialmente no solo como una mera asesina, sino por ser protagonista de las más graves infracciones que cualquier mujer podría cometer: se apropia del discurso y el poder masculino, comete adulterio, se convierte en ejecutora y sobre todo se atreve a legitimar sus acciones. Además, uno de los rasgos más terribles que se asocian a su personalidad es la doblez que manifiesta frente a la maternidad, un sentimiento completamente incomprensible en el mundo masculino. Por todo ello, Clitemnestra es recreada una y otra vez como un personaje femenino temible y peligroso, porque reúne en una persona todas aquellas características vetadas a las mujeres.

\section{Conclusiones}

La investigación se incluye en una reflexión sobre las relaciones de género en el imaginario griego. Quería desentrañar significados reveladores de lo que en las sociedades helenas podría haber supuesto "comportarse como una mujer" y "comportarse como un hombre». Y en especial valorar la apropiación de la palabra como vía de subversión femenina, analizando los procesos transgresores que Clitemnestra protagonizó. Estas son algunas de las observaciones más significativas que trazamos a modo de conclusiones.

Comenzamos por la necesidad de exponer una mirada crítica a la visión tradicional de la sociedad griega organizada en rígidas dicotomías (a través de la confrontación de contrarios: oikos/polis, privado/público, femenino/masculino, naturaleza/cultura) que se debería entender más como un reflejo de principios ideales que como una realidad del día a día (Nevett, 2011). En cuanto a la dicotomía mujer/hombre, que parecía ser sustancial en el 
pensamiento heleno, sostenemos que el asunto de la diferencia de género se complicaría si actúa en conjunción con otras cuestiones de análisis como el estatus, la edad, la clase o la etnia, esenciales para el estudio de las organizaciones comunitarias (Sebillote, 2015). En el caso de la antigua Grecia la posesión o la carencia de la ciudadanía, la libertad o la esclavitud, la capacidad socioeconómica, la minoría o mayoría de edad, la pertenencia étnica o la consideración como extranjero, fueron ingredientes influyentes que deben aplicarse conjuntamente con el factor género a la hora de analizar la situación de las mujeres y los hombres.

Con tal motivo, por encima de la generalización, se ha querido resaltar los matices que el análisis en función de las coordenadas espaciotemporales permite extraer. Específicamente se ha acentuado cómo la realidad femenina varió en función de los momentos históricos. De hecho, no se puede hablar de forma monolítica acerca de la condición de las mujeres griegas, ni establecer un recorrido lineal en la valoración femenina, puesto que a lo largo de los siglos se observan cambios de gran calado. También se ha subrayado el hecho de que el mundo griego estuvo organizado en torno a comunidades que concibieron su organización de formas distintas y otorgaron a las mujeres y lo femenino una valoración y protagonismo significativamente diferente. Los ámbitos dorio (esfera espartana y cretense) y jonio (Atenas y el área de influencia ateniense) llegaron a desarrollar matices tan importantes que llevaron al establecimiento de distintos códigos de género. Por último, se ha reflejado que la posición socioeconómica y las distinciones de edad y etnia influyeron directamente en la ideología de género.

Con todo, las convenciones sociales establecieron que la mujer se supeditase al varón, como un ser inferior e imperfecto que debía ser subordinado a través del control de su sexualidad, de la maternidad y de la mudez social. Y es que las mujeres no dejaron de ser vistas como un problema individual y colectivo de carácter social y político que debía gestionarse de forma estricta (Henry y James, 2012). Se estableció un ideal femenino de mujer respetable equivalente a esposa y madre, domesticada y fiel, al que se oponían todas aquellas mujeres que no se ajustaban a ese patrón. Precisamente, esta división nos ha permitido desentrañar la importancia del concepto de respetabilidad social, en especial para el universo femenino.

A medida que se consolidó el sistema democrático, se fue trazando una línea divisoria marcada entre mujeres y hombres tanto en el acceso al conocimiento como en la legitimidad para expresarse públicamente. En la mayor parte de las comunidades griegas -a excepción del área de influencia espartana-, se puede rastrear la exclusión femenina de los espacios y formas de socialización que 
tuvieron que ver con la palabra. Porque las mujeres respetables no debían tener un rol público ni tomar la palabra, y su voz carecía de poder y valoración social. De hecho, el pensamiento griego representó los lenguajes masculino y femenino como mundos opuestos, asociando a hombres y mujeres determinados géneros verbales reconocidos socialmente (McClure, 1999, 2001). El «habla de las mujeres» reflejaba su exclusión del logos y determinó numerosos estereotipos y prejuicios lingüísticos, de los cuales algunos todavía persisten: su lenguaje se caracterizaba por ser irreflexivo, indiscreto, engañoso y peligrosamente cautivador. Todas eran cualidades que se alineaban a la perfección con la necesidad de imponer el ideal de mujer que debe callar para ser discreta y respetable.

Otra conclusión importante es el reconocimiento de que la capacidad discursiva permite construir o deconstruir los códigos normativos del poder. En este caso, la investigación ha rescatado a Clitemnestra como protagonista de un complejo proceso transgresor respecto a los códigos de género. Un proceso subversivo tan extremo que la llevará convertirse en antimodelo de mujer y en símbolo de la rebeldía femenina frente a las normas. Ella representa la antítesis del ideal de mujer establecido en el ideario heleno, comenzando por su apropiación del discurso y por su creación de una voz propia, cargada de autoridad y legitimidad. Por esta misma cuestión se la representará como un personaje femenino virilizado, puesto que el mismo hecho de romper las ataduras del silencio requerido conllevaba ya una masculinización. Solo las mujeres que se mantenían calladas podían seguir siendo «verdaderas mujeres». Y el gran dilema en Clitemnestra es precisamente su carácter andrógino (Rodríguez Carmona, 2013: 101): nunca dejará de ser una mujer, aunque se virilice; ni tampoco dejará de ser madre, aunque de alguna manera reniega del sentimiento maternal.

El estudio minucioso de su figura nos ha llevado a sostener una posición de crítica firme frente a su frecuente caracterización simplista como esposa infiel, mala madre y mujer ambiciosa. Este retrato corresponde a un juicio corto de miras $y$, lo que es peor, contiene una carga negativa en la que aflora un análisis desde parámetros completamente estereotipados por la diferencia de género. Ella es mucho más que una mera representante de las «perversas»: encarna el reverso negativo de los roles femeninos porque ha transgredido las normas y constituye un auténtico peligro para el orden social establecido. Personifica un ejemplo inequívoco de la validez de la palabra como instrumento de subversión y representa a una mujer verdaderamente transgresora, que ha roto los límites impuestos al colectivo femenino $y$ se muestra «empoderada». 
Blok, Josine H. 2001. "Virtual Voices: Toward a Choreography of Women's Speech in Classical Athens». En Making Silence Speak. Women's Voices in Greek Literature and Society, editado por André Lardinois y Laura McClure, 95-116. Princeton, Nueva Jersey: Princeton University Press.

Bruit Zaidman, Louise. 1991. "Las hijas de Pandora. Rituales colectivos y prácticas de mujeres». En Historia de las mujeres I. La Antigüedad, editado por George Duby y Michelle Perrot, 373419. Barcelona: Círculo de Lectores.

Davidson, James. 2011. «Bodymaps: Sexing Space and Zoning Gender in Ancient Athens». Gender and History, 23 (3, November): 597614. DOI: $10.1111 /$ j.1468-0424.2011.01659.x

De Paco Serrano, Diana. 2003. "Caracterización de Clitemnestra y Agamenón de Esquilo a Séneca». Myrtia 18: 105-127.

Deslauriers, Marguerite. 2015. "Women, Education and Philosophy». En A Companion to Women in the Ancient World, editado por Sharon L. James y Sheila Dillon, 343-353. Oxford: WileyBlackwell.

Duby, George y Michelle Perrot. 1994. Historia de las mujeres I. La Antigüedad. Barcelona: Círculo de Lectores.

Dukelsky, Cora. 2011. "Clitemnestra, esposa violenta, mujer con poder. Una interpretación de su iconografía en la cerámica griega». En La pólis sexuada. Normas, disturbios y transgresiones del género en la Grecia antigua, editado por Elsa Rodríguez Cidre y Emiliano Jerónimo Buis, 85-113. Buenos Aires: Universidad de Buenos Aires.

Esteban Santos, Alicia. 2005. "Mujeres terribles (Heroínas de la literatura griega 1)». Cuadernos de filología clásica: Estudios griegos e indoeuropeos 15: 63-93.

-. 2006. «Esposas en guerra (esposas del ciclo troyano): (Heroínas de la mitología griega II)». Cuadernos de filología clásica: Estudios griegos e indoeuropeos 16: 85-105.

Esquilo. s. v a. C. La Orestea. Edición preparada por José Luis Calvo Martínez. 1984. Madrid: Editora Nacional.

Eurípides. s. V a. C. Tragedias II. Edición de Juan Miguel Labiano. 2016. Madrid: Cátedra.

Gallego, Julián. 2000. «Figuras de la tiranía, lo femenino y lo masculino en la Orestía de Esquilo. Studia Histórica. Historia antigua 18: 65-90. 
García Valdés, Manuela. 2006. "Lectura de un mito». En Koinós Lógos. Homenaje al profesor José García López, editado por Mariano Valverde Sánchez, Esteban Antonio Calderón Dorda y Alicia Morales Ortiz, 317-335. Murcia: Servicio de Publicaciones de la Universidad de Murcia.

González González, Marta. 2001. "Mujer, poder y discurso en la tragedia ateniense». Arenal. Revista de Historia de las mujeres 8 (1, enero-junio): 109-126.

-. 2011. "Lejos de Atenas. Mujeres griegas y literatura». En Ideas de mujer. Facetas de lo femenino en la Antigüedad, editado por Rosario López Grégoris y Luis Unceta Gómez, 107-130. Alicante: Universidad de Alicante, Centro de Estudios sobre la Mujer.

Henry, Madeleine M. y Sharon L. James. 2012. "Woman, City State: Theories, Ideologies, and Concepts in the Archaic and Classical Periods». En A Companion to Women in the Ancient World, editado por Sharon L. James y Sheila Dillon, 84-95. Oxford: Wiley-Blackwell.

Hesíodo. s. VIII-VII a. C. 1978. Obras y fragmentos. Teogonía; Trabajos y días; Escudo; Fragmentos; Certámen. Introducción, traducción y notas de Aurelio Pérez Jiménez y Alfonso Martínez Díez. Madrid: Gredos.

Homero. s. VIII a. C. 1996. a). Ilíada. Traducción, prólogo y notas de Emilio Crespo Güemes. Madrid: Gredos.

—. s. vilI a. C. 2011. b): Odisea. Traducción y prólogo de Carlos García Gual. Madrid: Alianza.

Iriarte, Ana. 1990. Las redes del enigma. Voces femeninas en el pensamiento griego. Madrid: Taurus.

-. (2002): De amazonas a ciudadanos. Pretexto ginecocrático y patriarcado en la Grecia antigua. Madrid: Akal.

Jenofonte. S. IV a. C. 1993. Recuerdos de Sócrates; Económico; Banquete; Apología de Sócrates. Introducciones, traducción y notas de Juan Zaragoza. Madrid: Gredos.

Jufresa, Montserrat. 1997. «Clitemnestra y la justicia». En Mujeres en la historia del pensamiento, editado por Amparo Ariño Verdú, 63-76. Barcelona: Anthropos.

Lauriola, Rosana. 2012. "The Woman's Place. An Overvirew in Classical Antiquity Through Three Exemplar Figures: Antigone, Clitemnestra and Medea». Revista Espaço Academico 130 (março): 27-44.

Loraux, Nicole. 1996. "Notas sobre un imposible sujeto de la historia». Enrahonar 26: 13-24. 
-. 2004. Las experiencias de Tiresias (lo masculino y lo femenino en el mundo griego). Barcelona: Acantilado.

Madrid, Mercedes. 1999. La misoginia en Grecia. Madrid: Cátedra.

Martínez López, Cándida. 1995. "Las mujeres y la ciudad en las sociedades mediterráneas clásicas». En Del patio a la plaza: Las mujeres en las sociedades mediterráneas, editado por Pilar Ballarín y Cándida Martínez López, 14-29. Granada: Universidad de Granada.

Marin Torres, Joan M. 2012. "Ciudadanía y género en Grecia. Fundamentos teóricos». En Variaciones sobre género, editado por Rosalía Torrent y Sonia Reverter, 55-65. Castellón: Acen.

McClure, Laura. 1999. Spoken like a Woman. Speech and Gender in Athenian Drama. Princeton, Nueva Jersey: Princeton University Press.

-. 2001. «Introduction». En Making Silence Speak: Women's Voices in Greek Literature and Society, editado por André Lardinois y Laura McClure, 3-16. Princeton, Nueva Jersey: Princeton University Press.

Miron Pérez, María Dolores. 2010. «Mujeres y poder en la Antigüedad clásica: Historia y Teoría Feminista». Saldvie. Estudios de prehistoria y arqueología 10: 113-125.

Molas Font, Maria Dolors. 2006. «Matrimonio y violencia en la ciudad-Estado griega patriarcal». En La violencia de género en la Antigüedad, editado por Maria Dolors Molas Font, Sonia Guerra López, Elisabet Huntingfort Antigas y Joana Zaragoza Gras, 7795. Madrid: Instituto de la Mujer.

-. 2012. «Desorden y transgresión en el mundo antiguo». Lectora 18: 13-16. DOI: 10.2436/20.8020.01.33.

Nevett, Lisa C. 2011. "Towards a Female Topography of the Ancient Greek City: Case Studies from Late Archaic and Early Classical Athens (c.520-400 BCE)». Gender and History, 23 (3, noviembre): 576-596. DOI: 10.1111/j.1468-0424.2011.01658.x

Orsi, Rocío. 2007. El saber del error: filosofía y tragedia en Sófocles. Madrid. México: Plaza y Valdés.

Píndaro s. VI-V a. C. 1984. Odas y fragmentos. Introducciones, traducción y notas de Alfonso Ortega. Madrid: Editorial Gredos.

Plácido Suarez, Domingo. 2000. «La presencia de la mujer griega en la sociedad: democracia y tragedia». Studia Histórica, Historia Antigua 18: 49-63.

Pomeroy, Sarah B. 1987. Diosas, esposas, rameras y esclavas. Mujeres en la Antigüedad Clásica. Madrid: Akal. 
-. 2002. Spartan women. Oxford: Oxford University Press.

Pomeroy, Sarah B. y otros. 2001. La antigua Grecia. Historia, política, social y cultural. Barcelona: Crítica.

Quintillá Zanuy, Teresa. 2005. «Los sexolectos o la caracterización del discurso femenino en el ámbito grecolatino». Faventia 27 (1): 45-62.

Rodríguez Carmona, Ana Belén. 2013. «El lenguaje de Clitemnestra en el Agamenón de Esquilo». Tycho. Revista de Iniciación en la Investigación del teatro clásico grecolatino y su tradición 1: 99118. Acceso del 3 de julio de 2016: http://www.uv.es/tycho/cas/01/rodriguez_ana.pdf.

Rose, Sonya O. 2012. ¿Qué es la historia de género?. Madrid: Alianza Editorial.

Sebillote Cuchet, Violaine. 2015. «Regímenes de género y Antigüedad griega clásica (siglos V-IV a. C.)». Revista de Historiografía 22: 51-81. Madrid: Universidad Carlos III. Acceso del 19 de abril de 2016: http://erevistas.uc3m.es/index.php/REVHISTO/article/view/2646/1446.

Scott, Joan. 1990. "El género: una categoría útil para el análisis histórico». En Historia y género: Las mujeres en la Europa moderna y contemporánea, editado por James S. Amelang y Mary Nash, 23-58. Valencia: Universidad de Valencia.

Sissa, Giulia. 1991. "Filosofías del género: Platón, Aristóteles y la diferencia sexual». En Historia de las mujeres I. La Antigüedad, editado por George Duby y Michelle Perrot, 73-111. Barcelona: Círculo de Lectores.

Sófocles. s. v a. C. 2009. Tragedias completas. Edición de José Vara Donado. Madrid: Cátedra.

Trümper, Monika. 2015. "Gender and Space, "Public" and "Private"». En A Companion to Women in the Ancient World, editado por Sharon L. James y Sheila Dillon, 288-303. Oxford: WileyBlackwell.

Tucídides. s. v a. C. 1952. Historia de la Guerra del Peloponeso. Traducción de Francisco Rodríguez Adrados. Madrid: Hernando.

Vernant, Jean-Pierre. 1992. Los orígenes del pensamiento griego, Barcelona: Paidós.

Zaragoza Gras, Joana. 2006. "La mujer como sujeto pasivo de la literatura griega». En La violencia de género en la Antigüedad, editado por Maria Dolors Molas Font, Sonia Guerra López, Elisabet Huntingfort Antigas y Joana Zaragoza Gras, 15-38. Madrid: Instituto de la Mujer. 